\title{
WITHIN AND BETWEEN-DAY DIFFERENCES IN ADOLESCENTS' OBJECTIVELY-MEASURED PHYSICAL ACTIVITY AND SEDENTARY BEHAVIOR
}

\author{
Jesús Viciana1, Daniel Mayorga-Vega ${ }^{1}$, and Maribel Parra-Saldías² \\ ${ }^{1}$ Department of Physical Education and Sport, University of Granada, Spain \\ ${ }^{2}$ Sport Observatory, University of Lakes, Santiago, Chile
}

Original scientific paper

DOI: $10.26582 / \mathrm{k} .51 .2 .13$

\begin{abstract}
:
A decline in adolescents' moderate-to-vigorous physical activity (MVPA) and the increase in their sedentary behavior (SB) have been registered all over the world. In order to increase the MVPA and reduce the SB of adolescents, their day has been analyzed by segments of time, verifying the contribution of each one to the daily recommendation of 60 minutes/day. Previous studies have been centered only on physical activity markers, but the SB variables nor the segments of the school-recess were not compared with the out-of-school period or with the weekend. This study aimed to examine the intra- and inter-days differences in the objectively measured levels of PA and SB in adolescents. A sample of 156 Chilean school students ( 87 boys and 69 girls; $\mathrm{M}$ age $=13.41$ years; $\mathrm{SD}=.67$ ) participated in the present study. Participants' PA and SB were objectively measured by a GT3X accelerometer. Overall results showed that only $14 \%$ and $9 \%$ of Chilean adolescents achieved the daily recommendation of 60 minutes of MVPA on weekdays and the weekend, respectively. School recess was found the best moment for developing MVPA, followed by out-ofschool time, with weekend days presenting the worst scenario. Regarding the SB, Chilean adolescents were involved in SB $69.39 \%$ of the time on weekdays, and over 70\% during the weekend. Different strategies are discussed in order to increase the MVPA and to decrease SB in each segment of a day.
\end{abstract}

Key words: accelerometry, school recess, out-of-school time, in-school time, leisure time, weekend

\section{Introduction}

Nowadays, the importance of achieving the recommendation of 60 minutes of daily moderateto-vigorous physical activity (MVPA) for children and adolescents (WHO, 2010) is well known, especially due to the demonstrated relationship with the maintenance of an active life through adulthood (Longmuir, Colley, Wherley, \& Tremblay, 2014). Unfortunately, the drop in adolescents' MVPA has being noticed all over the world (e.g., in Europe European Commission/Euridyce, 2013; the United States of America - United States Department of Human Services, 2010; or in Asian samples - Win, et al., 2015), and many researchers have focused on the study of this important variable for health and its surrounding circumstances. Sedentary behavior (SB) is increasing among the youth population and is associated with numerous unhealthy outcomes (Carson, et al., 2016). SB is an independent construct regarding physical activity (PA); it refers to any waking behavior that involves low levels of energy expenditure while in a sitting or reclining posture, and is conditioned by different motives and barriers compared to PA behavior (Sedentary Behaviour Research Network, 2012).

In order to improve the MVPA and SB outcomes in youth, many settings and personal characteristics have been studied to achieve a better understanding of the complex relationship between PA, individuals, and their contexts. Among the individuals' characteristics, gender has been considered as one of the most important (Viciana, MartínezBaena, \& Mayorga-Vega, 2015); female adolescents have been recognized as the more affected sector of the population in regard to low levels of PA and high levels of SB (Win, et al., 2015). Regarding the contexts and periods of time: (a) the school setting [Physical Education (PE), school recess, and totalschool-time (Mayorga-Vega, \& Viciana, 2015; Viciana, Mayorga-Vega, \& Martínez, 2016)]; (b) out-of-school or leisure time (Gillison, Standage, \& Skevington, 2011); and (c) weekdays and weekend days (registering the whole day as a period of time) have been analyzed in order to suggest different strategies for achieving the recommended criterion of daily MVPA. Moreover, contextual vari- 
ables belonging to the culture and society of the sample also influence the overall PA and SB of youth in each particular country (Moreno, Cano, Orellana, \& Kain, 2015; Morrisey, Janz, Letuchy, Shelby, \& Steven, 2015; Yli-Piipari, et al., 2016). For instance, in the meta-analysis by Brooke, Corder, Atkin, and van Sluijs (2014), the heterogeneity of results between studies was high due to these cultural variations, among other reasons. Beets, Bornstein, Beighle, Cardinal, and Morgan (2010) analyzed 43 studies from 13 countries, concluding that there were important variations between countries regarding PA (in steps). They found, for instance, that boys and girls from the European and Western Pacific regions had more steps per day than young people from the United States or Canada. In this line and regarding the LatinAmerican countries, results have shown a worrisome lack of PA and consequences with youth overweight and obesity [e.g., Álvarez, Ramírez, Ortiz, and Martínez (2013) in Puerto Rico; González et al. (2014) in Colombia; or Kain, Concha, Moreno, and Leyton (2014) in Chile]. Consequently, urgent interventions are needed in similar Latin-American cultures and a special attention should be paid to the time-segments of a day showing more physical inactivity.

The meta-analysis presented by Brooke et al. (2014) revised 37 selected studies that measured children and adolescents' PA (total and moderate-tovigorous) with accelerometers and compared days of the week and their several specific time-segments of the day (weekdays-weekends, in-schoolout-of-school, out-of-school-weekends, lessonstime-lunch-time). Conclusions revealed that children and adolescents were more active during weekdays than the weekend days. PE lessons and school recess were the most influential periods of time on weekdays regarding the total PA, and the out-of-school period was more influential regarding MVPA. Regarding the comparison between out-ofschool and weekend time, contrasting results were obtained. The difference in the total amount of PA was around 40 minutes in favor of the weekend (due to the total time being notably higher than in the out-of-school period), but the intensity was slightly higher in out-of-school time in comparison with the weekend (approximately 33 counts per minutes more). Particularly in Chile, two studies were found with objectively measured PA. The first one, carried out with pedometers, by Moreno et al. (2015), studied a sample of 250 children and obtained significant differences between weekdays (50.5 minutes) and weekend days (40.3 minutes); and between boys (54 minutes) and girls (45 minutes) during weekdays and weekend days (boys 42 minutes vs girls 37 minutes). The second study was carried out by Godard, Román, Rodríguez, Leyton, and Salazar (2012) with 109 children using accelerometers, and obtained significant differences in favor of boys achieving the recommendations of 60 minutes/day of MVPA ( $26.5 \%$ of boys more, $83.6 \%$ in total), and also in favor of weekdays compared to weekend days (951 counts per minute more).

Recently, Brooke, Atkin, Corder, Ekelund, and van Sluijs (2016) analyzed 769 English adolescents in a longitudinal study, observing that MVPA and total PA decreased along the years in all segments of the day on weekdays as well as on the weekends. This decrease was greater on the weekends than on weekdays, possibly due to the influence of PE lessons, which was the only segment where the MVPA did not decrease throughout the years. In accordance with this, Brusseau, Kulinna, Tudor-Locke, van der Mars, and Darst (2011) also concluded that the increment of PE lessons throughout the week could be a good solution for contributing to the increase of daily MVPA in the 363 American children studied.

Unfortunately, in the above commented study of Brooke et al. (2014), the authors of the various analyzed studies were centered only on two PA markers (MVPA and total PA). They did not compare the school-recess with the out-of-school period or with the weekend, and they did not analyze the SB variables, regardless of the importance that these analyses could have had for the adolescents' health. Moreover, although the habitual PA and SB are influenced by cultural aspects, as commented above, no research has been found (regarding the MVPA during different segments of the day) with Chilean adolescents, who are characterized by high indices of SB, low levels of PA, and, subsequently, high overweight and obesity ratios (Government of Chile, 2013; Kain, et al., 2014; Muros, et al., 2016).

Nevertheless, to know the objectively-measured behavior of Chilean adolescents in the different segments of the day (weekdays and weekends) could help researchers, PE teachers, health professionals, and university teachers from Chile to detect specific time-segments where PA declines and to focus on the detected problems in a better way. Thus, designing appropriate PA programs while considering important variables referred to in the present study in relation to PA and SB performed by Chilean adolescents in each segment of the day could provide more effective program strategies and activities. Therefore, the aim of this study was to examine the intra- and inter-days differences in the objectively measured levels of PA and SB in Chilean adolescents.

\section{Methods}

\section{Participants}

A sample of 156 Chilean secondary school students, 87 boys and 69 girls, from the municipal schools in the basic education level of eighth 
grade (i.e., 13-14 years of age) agreed to participate in the present study and met the inclusion criteria. The students belonged to the district called Nuñoa in Santiago of Chile (Chile). The inclusion criteria were: (a) being enrolled in the eighth grade of any selected school; (b) being free of any health disorder which would make them unable to undergo PA, and (c) presenting the corresponding signed consent by their parents or legal guardians. The exclusion criteria were: (a) to have not registered at least three weekdays with at least 600 minutes each; (b) to have not registered the two weekend days with at least 600 minutes each; (c) to have not registered at least three weekdays with at least 300 minutes belonging to in-school time; (d) to have not registered at least three weekdays with at least 300 minutes belonging to the out-of-school time period, and (e) to have not registered at least three weekdays with at least $95 \%$ of the school-recess time.

\section{Measures}

Firstly, participants' body mass and height were measured, and then the body mass index was calculated as body mass divided by body height squared $\left(\mathrm{kg} / \mathrm{m}^{2}\right)$. Participants wore shorts and T-shirts and were barefoot. They stood in the center of the scale for the body mass measurement (Tanita HD 313, Arlington, IL, USA; accuracy $=.1 \mathrm{~kg}$ ), without support, and with the weight distributed evenly on both feet. For the body height measurement, participants stood with the feet together, their heels, buttocks and upper part of the back touching the stadiometer (SECA 206®, Hamburg, Germany; accuracy $=.1 \mathrm{~cm}$ ), and with the head placed in the Frankfort plane. Both variables were measured twice and the average of each was calculated (ISAK, 2001). Finally, participants' overweight was categorized according to the international cut-off values of the body mass index (BMI) as not-overweight (BMI<overweight cut-point) and overweight (BMI $\geq$ overweight cut-point) (Cole, Bellizzi, Flegal, \& Dietz, 2000).

Participants' PA and SB were objectively measured by a GT3X accelerometer (ActiGraph, LLC, Pensacola, FL, USA). The GT3X accelerometer is a compact $(3.8 \times 3.7 \times 1.8 \mathrm{~cm})$, lightweight $(27 \mathrm{~g})$, and triaxial monitor designed to record time of varying accelerations ranging in magnitude from approximately .05 to 2.50 Gs. The accelerometer output is digitized by a 12-bit analog-to-digital converter at rates of $30-100 \mathrm{~Hz}$. Then, the signal passes through a digital filter that band limits the accelerometer to the frequency range of $.25-2.5 \mathrm{~Hz}$. The filtered signal is then rectified and integrated over a userspecified interval of time known as an epoch. At the end of each epoch, the summed value known as "activity count" or counts is stored in its memory and the integrator is reset. The counts obtained in a particular epoch are proportional to the intensity of the PA during the measured period (Trost, Loprinzi, Moore, \& Pfeiffer, 2011). One of the measurements offered by the accelerometer is the vertical axis variable, which is the magnitude vector of linear acceleration in the vertical movements that provides the values of PA levels.

After adolescents' PA and SB were monitored, data were downloaded and analyzed using the ActiLife Lifestyle Monitoring System Software version 6.13.2. To avoid biases due to participants' reactivity, data of the first day were considered as a day of familiarization and were not used for statistical analyses. The in-school time and school-recess time were registered according to the schools' schedules. The out-of-school period was registered from the end of the school time to the end of the day (i.e., 23:59 pm). The lesson-time was calculated as the in-school time minus the school-recess time, including PE classes as well, as previous research have registered (Brooke, et al., 2014). Nevertheless, there are also differences in previous studies, for instance, in the definition of in-school time depending on the objective of the study [e.g., Silva, Santos, Welk, and Mota (2011) defined the in-school time including PE and recess time (from 8 a.m. to 6 p.m.), because their objective was to compare the in-school time with the out-of-school time, without taking into account other periods such as recess time or lesson time]. Non-wear periods were defined as default when a minimum length of 60 minutes of consecutive zero-count epochs with up to a two minutes spike tolerance was reached (Oliver, Badland, Schofield, $\&$ Shepherd, 2011). According to previous studies (e.g., Mayorga-Vega, Martínez-Baena, \& Viciana, 2018), to avoid potential bias due to differences in the length of the total valid wear time of any analyzed period, valid wear time-based standardized scores were used (e.g., for the MVPA during a whole day, the percentage of time that participants spent in MVPA in relation with the total valid wear time during the day was used instead of the total minutes spent in MVPA; or the steps/minute were referred to as the number of steps per minute performed by the participant during the valid wear time registered in each of the segments of the day). The percentage of time spent in sedentary activities, light activities, and MVPA was determined using Evenson's cut-off points (Evenson, Catellier, Gill, Ondrak, \& McMurray, 2008; Trost, et al., 2011). Counts per minute recorded in the vertical axis, also known as $y$-axis or axis 1 , were calculated. Step counts per minute were assessed by withininstrument processing of the number of cycles in the accelerometer signal or cycle counts. Sedentary variables were calculated with a minimum length of 10 minutes and/or count levels of $<100$ (Treuth, et al., 2004; Trost, et al., 2011). Particularly, (a) sedentary $(\%)$ was calculated as the percentage of time 
equal or below 100 counts per minute regardless of the bouts of time; (b) sedentary bouts (bouts $/ h$ ) were defined as the number of bouts (per hour) with a minimum length of at least 10 minutes and below 100 counts per minute, and (c) total time in sedentary bouts (minutes/hour) was calculated as the total time (expressed in minutes and divided by hour) spent during the bouts (bout with a minimum length of 10 minutes and below 100 counts per minute).

ActiGraph accelerometer-measured PA and SB has shown a high reliability and validity among adolescents (Santos-Lozano, et al., 2013; Trost, et al., 2011), adults and older people.

\section{Procedure}

The protocol of the present study was first approved by the Ethical Committee of the University of Granada. Afterward, a researcher contacted the principals and PE teachers of each of the 10 municipal schools of the basic education level belonging to the Community of Nuñoa in Santiago of Chile. They were informed of the project and the permission to conduct the study was requested. After the approvals of four schools had been obtained, the eighth-grade students and their legal guardians were fully informed of all the features of the study, and a written informed consent was obtained from all the participants' legal guardians to take part in the study.

All data collection was done during the months of July (last week) to October (first three weeks) of 2015, except the third week of September due to a national holiday. Therefore, data were collected in the winter and in the beginning of the fall season (with a minimum temperature range of $5^{\circ}-10^{\circ}$ Celsius and a maximum range of $15^{\circ}-25^{\circ}$ Celsius). Cooler temperatures and less rainfall than usual characterized the study's data collection period in 2015.

During a PE class, a trained researcher fitted the accelerometers on the right hip of all the participants using an elastic waistband. Participants were instructed to wear the accelerometer for eight consecutive days, from waking up to bedtime, and to take the accelerometer off only when engaged in aquatic activities or taking a shower. Adoles- cents were also urged to maintain their normal PA habits. School recess was distributed in a different way according to each school's rules, but there were three school recesses that ranged between 10 to 30 minutes each (with a total amount of 60 minutes). The students had to go out on the school grounds (it was forbidden to leave the school center) and the surface was hard (cement) in all schools that participated in the study. Students wore school uniforms and they shared the school recess space with other mates of the same educational level.

\section{Statistical analyses}

Descriptive statistics for the general characteristics, PA and SB variables of the studied participants were calculated. Mann-Whitney and Chisquared tests were used to compare general characteristics between the male and female adolescents. Wilcoxon test was applied to examine the differences in objectively determined PA levels and SB between the following segments: weekdaysweekend, in-school-out-of-school, lessonsschool recess, weekend-out-of-school, out-ofschool—school recess, and weekend - school recess (Figure 1). Additionally, McNemar test was used to compare the proportion of adolescents that achieved the daily recommendation of 60 minutes of MVPA (WHO, 2010) and 10,000 steps (Tudor-Locke, et al., 2011) between weekdays and weekend days. All analyses were conducted for the total sample, as well as separately by gender. All statistical analyses were performed using the SPSS Version 21.0 for Windows (IBM ${ }^{\circledR}$ SPSS ${ }^{\circledR}$ Statistics). The statistical significance level was set at $\mathrm{p} \leq .05$.

\section{Results}

\section{General characteristics}

From the initial sample of 156 students who participated in the present study, 45 adolescents (23 boys and 22 girls) were eliminated due to meeting one or more exclusion criteria. Table 1 shows the general characteristics of the studied participants. The results of the Mann-Whitney U test showed that, on average, male adolescents were statistically taller than female adolescents $(\mathrm{p}<.05)$. However,

Table 1. General characteristics of participants (average and standard deviation/frequency), and differences between the male and female adolescents

\begin{tabular}{|c|c|c|c|c|}
\hline & $\begin{array}{c}\text { Total } \\
(n=111)\end{array}$ & $\begin{array}{l}\text { Males } \\
(n=64)\end{array}$ & $\begin{array}{c}\text { Females } \\
(n=47)\end{array}$ & $p^{a}$ \\
\hline Age (years) & $13.41(.67)$ & $13.53(.71)$ & $13.26(.57)$ & - \\
\hline Body mass (kg) & $58.27(10.51)$ & $58.96(11.51)$ & $57.32(9.02)$ & .639 \\
\hline Body height (cm) & $163.78(7.66)$ & $166.50(7.88)$ & $160.09(5.58)$ & $<.001$ \\
\hline Body mass index $\left(\mathrm{kg} / \mathrm{m}^{2}\right)$ & $21.69(3.43)$ & $21.20(3.41)$ & $22.37(3.38)$ & .031 \\
\hline Not-overweight/overweight-obesity & $75 / 36$ & $46 / 18$ & $29 / 18$ & .258 \\
\hline
\end{tabular}

Note. ${ }^{a}$ Significance levels of the Mann-Whitney $U$ test for body mass, body height, and body mass index, and Chi-squared test for the ratio not-overweight:overweight-obese. 


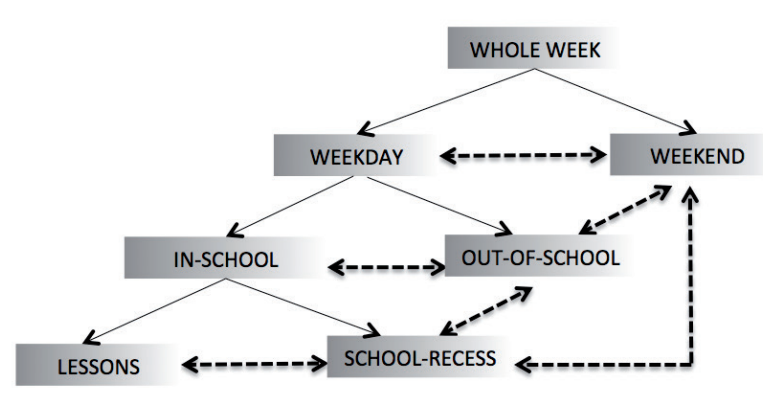

Figure 1. Comparative analyses of physical activity levels and sedentary behaviors between time segments of the day and week (dashed lines with double arrows).

female adolescents had statistically higher body mass index values $(\mathrm{p}<.05)$. For the body mass no statistical difference was found ( $p>05$ ). The results of the Chi-squared test showed that both groups had a balanced representation of overweight/obese and not-overweight adolescents $(\mathrm{p}>.05)$.

\section{Physical activity}

Table 2 shows the objectively measured PA levels of the studied Chilean adolescents.

Weekdays vs Weekend. The results of the Wilcoxon test showed that the total sample, as well as male and female adolescents independently, had higher PA levels on weekdays than on the weekend $(\mathrm{p}<.05)$.

Figure 2 represents the percentage of adolescents achieving the daily recommendation of 60 minutes of MVPA and 10,000 steps on weekdays and during the weekend. The results of the

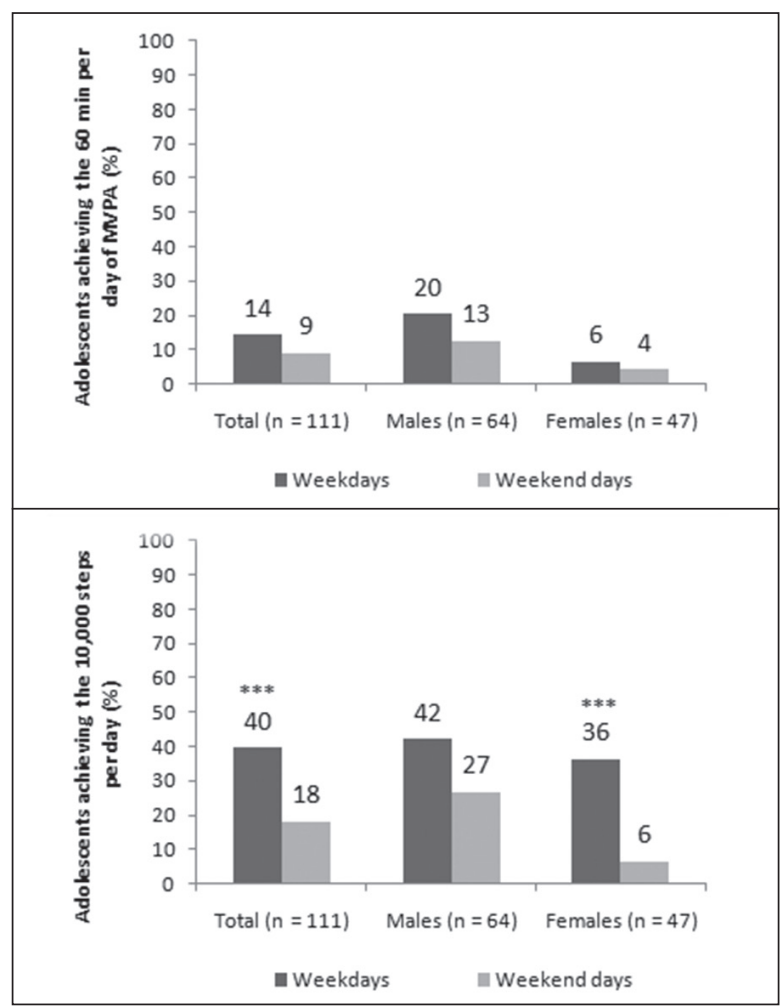

Figure 2. Percentage of adolescents achieving the daily recommendations of 60 minutes of MVPA (above) and 10,000 steps (below) on weekdays and weekend days. Results of McNemar test (*** $p \leq .001)$.

Table 2. Objectively-measured physical activity levels in Chilean adolescents (*)

\begin{tabular}{|c|c|c|c|c|c|c|}
\hline & \multicolumn{2}{|c|}{ Week } & \multicolumn{2}{|c|}{ Day } & \multicolumn{2}{|c|}{ In-school } \\
\hline & Weekdays & Weekend & In-school & Out-of-school & Lessons & School recess \\
\hline & $M(S D)$ & $M(S D)$ & $M(S D)$ & $M(S D)$ & $M(S D)$ & $M(S D)$ \\
\hline \multicolumn{7}{|l|}{ Total $(n=111)$} \\
\hline $\begin{array}{l}\text { Vertical axis } \\
\text { (counts/min) }\end{array}$ & $284.22(104.76)$ & $219.63(120.06)$ & 312.07 (135.71) & $353.84(167.29)$ & $260.16(108.89)$ & $605.93(414.98)$ \\
\hline Steps (steps/min) & $8.12(2.67)$ & $5.84(3.26)$ & $9.50(3.62)$ & $9.66(3.98)$ & 7.69 (3.02) & $19.81(11.01)$ \\
\hline MVPA (\%) & $3.25(2.04)$ & $2.06(2.10)$ & $3.18(2.57)$ & $4.37(3.21)$ & $2.57(1.97)$ & $6.49(9.14)$ \\
\hline Light (\%) & $27.36(5.82)$ & $25.39(7.35)$ & $31.70(8.66)$ & $30.80(8.08)$ & $28.51(9.24)$ & $50.23(11.82)$ \\
\hline \multicolumn{7}{|l|}{ Males $(n=64)$} \\
\hline $\begin{array}{l}\text { Vertical axis } \\
\text { (counts/min) }\end{array}$ & $300.36(113.60)$ & $238.25(132.12)$ & $341.83(140.95)$ & $375.78(190.58)$ & $270.71(99.46)$ & $739.70(484.62)$ \\
\hline Steps (steps/min) & $8.20(2.83)$ & $6.24(3.59)$ & $9.96(3.86)$ & $9.75(4.33)$ & $7.68(2.82)$ & $22.63(12.83)$ \\
\hline MVPA (\%) & $3.59(2.13)$ & $2.47(2.40)$ & $3.74(2.63)$ & $4.83(3.62)$ & $2.70(1.61)$ & $9.39(10.94)$ \\
\hline Light (\%) & $27.58(6.53)$ & $25.76(7.63)$ & $33.11(9.19)$ & $30.72(8.98)$ & $29.86(9.91)$ & $51.57(11.57)$ \\
\hline \multicolumn{7}{|l|}{ Females $(n=47)$} \\
\hline $\begin{array}{l}\text { Vertical axis } \\
\text { (counts/min) }\end{array}$ & $262.25(87.83)$ & $194.27(97.06)$ & 271.56 (117.99) & 323.96 (124.90) & $245.78(120.17)$ & $423.78(177.12)$ \\
\hline Steps (steps/min) & $8.02(2.46)$ & $5.28(2.68)$ & $8.88(3.21)$ & $9.54(3.49)$ & $7.70(3.29)$ & $15.96(6.16)$ \\
\hline MVPA (\%) & $2.78(1.83)$ & $1.51(1.46)$ & $2.42(2.31)$ & $3.74(2.46)$ & $2.38(2.39)$ & $2.56(2.88)$ \\
\hline Light (\%) & $27.06(4.74)$ & $24.9(7.00)$ & $29.78(7.55)$ & $30.90(6.76)$ & $26.66(7.97)$ & $48.41(12.04)$ \\
\hline
\end{tabular}

Note. $\mathrm{M}=$ mean; $\mathrm{SD}=$ standard deviation; MVPA=moderate-to-vigorous physical activity; $\left({ }^{*}\right)$ Detailed information about the measurement unit used for each variable is reported in the Measures section. 
McNemar test showed that the proportion of adolescents achieving the daily recommendation of steps was statistically higher on weekdays than on the weekend $(p<.001)$. However, for the recommendation of 60 minutes per day of MVPA no differences were found $(\mathrm{p}>.05)$. Regarding the results separately by gender, a higher proportion of female adolescents achieved the daily recommendation of steps on weekdays than on the weekend $(p=.001)$, while for male adolescents it was not statistically significant ( $p>05$ ). For the recommendation of 60 minutes per day of MVPA no differences were found either in male or female adolescents ( $\mathrm{p}>.05)$.

In-school vs Out-of-school. The results of the Wilcoxon test showed statistically higher levels of vertical axis and MVPA during out-of-school than in-school time $(p<.05)$. Regarding the results separately by gender, female adolescents showed a higher amount of time in out-of-school MVPA $(\mathrm{p}<.001)$, while in male adolescents no difference was detected $(p>05)$. Female adolescents also showed higher levels of vertical axis for out-ofschool than in-school time $(\mathrm{p}<.01)$. However, male adolescents showed higher levels of light PA during in-school than out-of-school time $(p<.05)$. For the rest of the variables no statistical differences were found ( $\mathrm{p}>.05)$.

Lessons vs School recess. The results of the Wilcoxon test showed that adolescents obtained higher levels of PA in school-recess time than in lesson time $(\mathrm{p}<.001)$. Regarding the results separately by gender, both the male and female adolescents had statistically higher PA levels during school recess than lessons time $(\mathrm{p}<.05)$, except for the female adolescents' MVPA, in which statistically significant differences were not found ( $\mathrm{p}>.05$ ).

Weekend vs Out-of-school. The results of the Wilcoxon test showed that the total sample, as well as both the male and female adolescents separately, had higher levels of PA in out-of-school time than on the weekend $(\mathrm{p}<.001)$.

Out-of-school vs School recess. The results of the Wilcoxon test showed that, overall, adolescents had higher values of vertical axis, steps, and light PA in school-recess time than in out-of-school time $(\mathrm{p}<.05)$. For MVPA no statistically significant differences were found ( $\mathrm{p}>.05)$. Regarding the gender, male adolescents had higher levels of PA in school-recess time than in out-of-school time $(p<.01)$. Female adolescents had higher values of vertical axis, steps, and light PA during school recess than during out-of-school time $(\mathrm{p}<.01)$, but the time spent in MVPA was statistically higher in out-of-school time than in school-recess time $(\mathrm{p}<.05)$.

Weekend vs School recess. The results of the Wilcoxon test showed that adolescents had statistically higher PA levels in school recess than during the weekend $(p<.05)$. Regarding the results sepa- rately by male and female adolescents, both gender categories had statistically higher levels of PA in school-recess than on the weekend $(\mathrm{p}<.05)$.

\section{Sedentary behavior}

Table 3 shows the objectively measured SB levels of the Chilean adolescents.

Weekdays vs weekend. The results of the Wilcoxon test showed that the total sample, as well as both the male and female adolescents independently, had statistically significantly lower values of $\mathrm{SB}$ on weekdays than during the weekend $(\mathrm{p}<.05)$.

In-school vs Out-of-school. The results of the Wilcoxon test showed that both the total sample and male adolescents had a statistically significantly higher number of sedentary bouts during out-ofschool than in-school time $(\mathrm{p}<.01)$. However, female adolescents showed a statistically higher percentage of sedentary time and total time of sedentary bouts during in-school than out-of-school time $(\mathrm{p}<.05)$. For the rest of variables, no statistically significant differences were found ( $\mathrm{p}>.05)$.

Lessons vs School recess. The results of the Wilcoxon test showed that both in the total sample as well as in the male and female adolescents women independently had statistically higher values of SB during lessons time than in school-recess $(\mathrm{p}<.001)$.

Weekend vs Out-of-school. Results of the Wilcoxon test showed that the total sample, as well as the male and female adolescents separately, had statistically significantly higher values of SB during the weekend than in out-of-school time $(\mathrm{p}<.05)$.

Out-of-school vs School recess. The results of the Wilcoxon test showed that both the total sample as well as the male and female adolescents independently had statistically higher values of SB in out-of-school time than in school-recess $(\mathrm{p}<.001)$.

Weekend vs School recess. Results of the Wilcoxon test showed that the total sample, as well as the male and female adolescents independently, had statistically significant higher values of SB on the weekend than during school-recess $(\mathrm{p}<.001)$.

\section{Discussion and conclusions}

The aim of this study was to examine the intraand inter-days differences in the objectively measured levels of PA and SB in Chilean adolescents. Overall results showed that only a worrisome $14 \%$ and $9 \%$ of Chilean adolescents achieved the international recommendation of 60 minutes of MVPA on weekdays and weekends, respectively. Special attention should be focused on female adolescents with only $6 \%$ and $4 \%$ of MVPA on weekdays and weekends, respectively. Our findings are in accordance with previous results presented in literature, although in the present study the percentages of the sample reaching the MVPA were even lower (Brusseau \& Kulinna, 2015; Currie, et al., 2012; Dudley, Okely, Cotton, Pearson, \& Caputi, 2012; Gao, Chen, 
Table 3. Objectively-measured levels of sedentary behavior in Chilean adolescents (*)

\begin{tabular}{|c|c|c|c|c|c|c|}
\hline & \multicolumn{2}{|c|}{ Week } & \multicolumn{2}{|c|}{ Day } & \multicolumn{2}{|c|}{ In-school } \\
\hline & Weekdays & Weekend & In-school & Out-of-school & Lessons & School recess \\
\hline & $M(S D)$ & $M(S D)$ & $M(S D)$ & $M(S D)$ & $M(S D)$ & $M(S D)$ \\
\hline \multicolumn{7}{|l|}{ Total $(n=111)$} \\
\hline Sedentary $(\%)^{a}$ & $69.39(6.77)$ & $72.54(8.54)$ & $65.12(10.11)$ & $64.84(9.50)$ & $68.92(10.05)$ & $43.27(16.17)$ \\
\hline $\begin{array}{l}\text { Sedentary bouts } \\
\text { (bouts/h) }\end{array}$ & $1.18(.18)$ & $1.24(.24)$ & $1.06(.23)$ & $1.15(.28)$ & $1.16(.24)$ & $.50(.41)$ \\
\hline $\begin{array}{l}\text { Total time in sedentary } \\
\text { bouts }(\mathrm{min} / \mathrm{h})\end{array}$ & $28.58(5.52)$ & $30.86(7.10)$ & $25.05(8.38)$ & $23.99(8.04)$ & $28.16(9.31)$ & $7.22(6.18)$ \\
\hline \multicolumn{7}{|l|}{ Males $(n=64)$} \\
\hline Sedentary $(\%)^{a}$ & $68.83(7.60)$ & 71.77 (9.15) & $63.16(10.78)$ & $64.46(10.55)$ & $67.44(10.63)$ & 39.05 (17.36) \\
\hline $\begin{array}{l}\text { Sedentary bouts } \\
\text { (bouts/h) }\end{array}$ & $1.18(.20)$ & $1.23(.24)$ & $1.03(.23)$ & $1.13(.31)$ & $1.14(.25)$ & $.41(.38)$ \\
\hline $\begin{array}{l}\text { Total time in sedentary } \\
\text { bouts }(\mathrm{min} / \mathrm{h})\end{array}$ & $28.19(6.05)$ & $30.19(7.52)$ & $23.58(8.66)$ & $23.62(8.83)$ & $26.66(9.60)$ & $5.97(5.86)$ \\
\hline \multicolumn{7}{|l|}{ Females $(n=47)$} \\
\hline Sedentary $(\%)^{a}$ & $70.16(5.42)$ & 73.6 (7.61) & $67.8(8.52)$ & $65.35(7.94)$ & 70.95 (8.92) & $49.03(12.42)$ \\
\hline $\begin{array}{l}\text { Sedentary bouts } \\
\text { (bouts/h) }\end{array}$ & $1.18(.15)$ & $1.26(.24)$ & $1.1(.22)$ & $1.16(.23)$ & $1.18(.23)$ & $.63(.42)$ \\
\hline $\begin{array}{l}\text { Total time in sedentary } \\
\text { bouts }(\mathrm{min} / \mathrm{h})\end{array}$ & $29.1(4.73)$ & $31.78(6.45)$ & 27.04 (7.62) & $24.5(6.87)$ & $30.21(8.57)$ & $8.91(6.25)$ \\
\hline
\end{tabular}

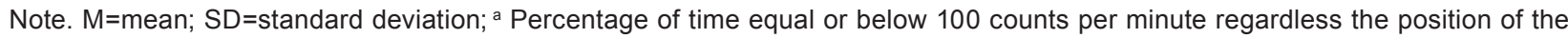
participants or bouts of time; $\left(^{*}\right)$ Detailed information about the measurement unit used for each variable is reported in the Measures section.

Huang, Stodden, \& Xiang, 2017). Moreover, lower levels of MVPA were more commonly registered in female than in male adolescents (Mielgo-Ayuso, et al., 2016). General considerations such as the climate in winter, which is not the best period to maintain high levels of PA, could have influenced these lower levels of MVPA results obtained in the present study [e.g., Merrill, Shields, White, and Druce (2005) detected 5\% less participants meeting the recommendations for PA in winter than in spring or summer in the United States of America]. Nevertheless, previous research with self-reported measurements also registered low levels of MVPA in Chilean adolescents (e.g. Government of Chile, 2013; Kain, et al., 2014; Muros, et al., 2016).

In regard to the PA levels obtained in the different periods of the day, school recess stands as the best segment of the day where adolescents develop the maximum percentage of time involved in MVPA in relation to its total available time (schedule time). However, after an extensive analysis of these results, it is necessary to denote that the contents of school recess are unstructured and depend on the will of adolescents. From this point of view, the adolescents studied dedicated only $6.49 \%$ of that time to MVPA, which is limited regarding, for instance, $11 \%$ obtained with Spanish adolescents by Viciana et al. (2016), or taking into account that recess has contributed to up to $40 \%$ of the recommended daily PA in previous research (Ridgers, Stratton, \& Fairclough, 2006).
Some factors could influence these results, such as the surface of the recreation area, for instance. Andersen, Klinker, Toftager, Pawlowki, and Schipperijn (2015) obtained that solid surfaces, like the ones in the school centers studied in the present research, had the highest proportion of time spent sedentary in contrast to the playground and grass surfaces, which had the highest proportion of time involved in PA. The over-crowdedness of the recreational area reserved for the school recess could also influence the results of the present study. After observing eight South African Primary schools, Uys et al. (2015) suggested that over-crowdedness of the recreational area during school recess was a detrimental factor for obtaining higher MVPA levels, while the SB increased. A final reason for the results obtained in this study regarding low levels of MVPA during recess could be associated with the use of uniforms in the participating students. School uniforms have been identified previously in qualitative research as a barrier to perform PA (Parrish, Yeatman, Iverson, \& Russell, 2012; Stanley, Boshoff, \& Dollman, 2012; Watson, Eliott, \& Mehta, 2015). Students perceived their uniforms as uncomfortable, hot to run in, and manifested their preference of shorts and T-shirts for playing (clothing that allows movements). In line with the previously commented factors, conclusions should be focused on recommending playground and grass surfaces; also, school administrations should stagger school recesses for different educa- 
tional levels within the center's schedule in order to provide more space for adolescents to play in, and the use of school uniforms should be avoided (or at least to allow the use of comfortable uniforms should be allowed to promote PA).

School recess is considered crucial for the increase of MVPA in youth, so much so that augmenting the duration and frequency of schoolrecess periods has been recommended in literature (Viciana, et al., 2016). However, results of the present study suggest that the key factor is not the proposed increment of its duration and frequency, but the offer of optional and motivational programs that will make adolescents more involved in MVPA for a longer time during this period. Making adolescents decide under their will to participate voluntarily in MVPA is not a good solution because they are not as active as would be desired by themselves. Other initiatives for in-school time have also been implemented with success. For instance, the Active School Day performed in several Boston Public Schools obtained good results incrementing the weekly minutes of MVPA by 150 in PE lessons, as well as in school recess for the students involved in that initiative (Cradock, et al., 2014).

Despite the above comments, from the perspective of daily time segments that only depended on the will of the adolescents to be involved in MVPA or not, school recess was found as the best moment for developing MVPA, followed by out-of-school time, and ending with weekend days presenting the worst scenario. Therefore, it seems that weekend and out-of-school periods need an urgent intervention in order to improve this situation in Chilean adolescents, particularly considering that these two periods are much longer than school recess. Moreover, previous studies have verified the decrease of MVPA during these two periods (weekend and outof-school time) throughout the years, as happened with the results obtained in the longitudinal study by Brooke et al. (2016). In Chile, the Scholar Health World Survey, carried out with 8,131 adolescents between 13-15 years of age in municipal and subsidised schools from Tarapacá, Biobío, Valparaíso, and the Metropolitan area, already detected only $15 \%$ and $8 \%$ of boys and girls were ative enough regarding the 60 minutes/day recommendation with only $40 \%$ of boys and $20 \%$ of girls practicing MVPA out-of-school, respectively (Chilean Ministry of Health/WHO, 2005). Several factors have been associated with low levels of PA during out-of-school time in international contexts, as reflected the meta-analysis carried out by Lee et al. (2015). Parental restrictions/facilitations and neighbourhood safety; play spaces, accessibility, maintenance, and proximity to sports facilities; reduced sense of community or policy issues are factors associated with PA in out-of-school time that should be taken into account in further studies, probably with qualitative studies in communities like the one studied in the present study. Some alternatives are discussed in literature with regard to solving this problem: (a) to offer appropriate proposals of MVPA by the community, and municipal initiatives during leisure time (for out-of-school and weekend periods) (Moore, Brinkley, Morris, Oniffrey, \& Kolbe, 2016); (b) to develop collaborative programs between PE teachers and families, in which adolescents' parents and friends participate in order to increase the total time involved in MVPA during weekends and out-of-school time (Morrisey, et al., 2015); and (c) to organize extracurricular sports programs delivered by capable professionals could also contribute to the increase of MVPA during out-of-school time, mainly those developed in the school center after the in-school period (MayorgaVega \& Viciana, 2015). Nevertheless, the demonstrated relationship between sports facilities and the practice of PA in leisure time (Fórnias, et al., 2015) suggests that PE teachers should provide adolescents with knowledge regarding the localization of sports facilities, urban and natural spaces, as well as the appropriate procedures to use them in order to increase MVPA during the out-of-school period.

The studied Chilean adolescents were involved in SB a worrisome $69.39 \%$ of the time on weekdays, and over $70 \%$ on weekends, with the female adolescents again being more sedentary than the male adolescents. Considering that the lesson time is dedicated almost exclusively to attending theoretical classes (except PE lessons), out-of-school and school-recess periods stand as the main focus of change aiming to decrease as much as possible the SB results obtained in the present study.. These results are also in accordance with previous research (Arundell, Hinkley, Veitch, \& Salmon, 2015; Ridgers, Timperio, Crawford, \& Salmon, 2013), although the total amount of time dedicated to SB by Chilean adolescents was even higher.

As suggested by previous researchers (Viciana, et al., 2015), the proposal to increase PE days in the week could be a good solution to resolve this situation. Nevertheless, academics and PE teachers do not have the authority to decide on this issue, as it is up to the politicians who are in charge of the organization of the curriculum of Chilean youth. Moreover, previous studies have confirmed systematic evidences regarding the effects of new technologies in reducing SB (Gao \& Chen, 2014). A new trend, the exergames, has been studied and implemented as a valid alternative to conventional MVPA, such as jogging. Exergames refers to active video games and they are considered a good strategy for increasing MVPA due to their motivating nature, instead of the conventional passive video games (Gao, et al., 2017). Some active games (e.g., Dance Dance Revolution) are even considered to be as active as conventional MVPA activities (Gao \& Chen, 2014). A second technological alter- 
native for increasing PA is related to new mobile apps. Some applications like Pokémon Go (Althoff, White, \& Horvitz, 2016) could decrease the total time in SB, and other more ambitious mobile apps could increase MVPA or even improve diet habits (Recio-Rodríguez, et al., 2016).

Although in the present research the type of activities performed by adolescents were not registered during the SB time in the out-of-school and weekend periods, it is highly probable that adolescents had higher levels than desirable of different types of screen viewing habits (e.g., television, or traditional video-games), as confirmed by other researchers in Chile (Braithwaite, et al., 2013). Consequently, exergaming or mobile apps could be excellent strategies to implement in this kind of population, possibly organizing and previously selecting several specific games and applications that have shown effectiveness in regard to an active participation by adolescents.

Finally, the mentioned strategy of MVPA initiatives by communities and municipal organizations could also be effective in increasing MVPA and reducing the $\mathrm{SB}$ of Chilean adolescents. Cohen et al. (2013) already revealed that some initiatives performed in the community environment could increase PA developed in the United States' urban parks. In their study, the total number of persons per week who went to the parks to practice PA increased by 600 , and an increment of 1,830 MET-hours/week regarding energy expenditure was registered in the 50 parks from Los Angeles that participated in data collection. Thus, these kinds of strategies could also be implemented in order to reduce the total time spent in SB and increase the MVPA of Chilean adolescents.

In conclusion, a very low percentage of Chilean adolescents achieved the international recommendation of daily MVPA, while registering ominously high levels of SB. Consequently, the above commented strategies should be taken into consideration in order to solve this problem regarding the different time segments of the day for Chilean adolescents.

\section{References}

Althoff, T., White, R.W., \& Horvitz, E. (2016). Influence of Pókemon Go on physical activity: Study and implications. Journal of Medicine Internet Research, 18(2), e315.

Álvarez, A.J., Ramírez, F.A., Ortiz, A., \& Martínez, L.R. (2013). Niveles de actividad física en mujeres adolescentes en Puerto Rico: Un estudio piloto. [Physical activity levels in female adolescents of Puerto Rico: A pilot study. In Spanish.]. Pensar en Movimiento, 11(1), 1-12.

Andersen, H.B., Klinker, C.D., Toftager, M., Pawlowki, C.S., \& Schipperijn, J. (2015). Objectively measured differences in physical activity in five types of schoolyard area. Landscape Urban Plan, 134, 83-92.

Arundell, L., Hinkley, T., Veitch, J., \& Salmon, J. (2015). Contribution of the after-school period to children's daily participation in physical activity and sedentary behaviours. Plos One, 10(10), e0140132.

Beets, M.W., Bornstein, D., Beighle, A., Cardinal, B.J., \& Morgan, C.F. (2010). Pedometer-measured physical activity patterns of youth: A 13 countries review. American Journal of Preventive Medicine, 38(2), 208-216.

Braithwaite, I., Stewart, A.W., Hancox, R.J., Beasley, R., Murphy, R., Mitchell, E.A., et al. (2013). The worldwide association between television viewing and obesity in children and adolescents: Cross sectional study. Plos One, 8(9), e74263.

Brooke, H.L., Atkin, A.J., Corder, K., Ekelund, U., \& van Sluijs, E.M. (2016). Changes in time-segment specific physical activity between ages 10 and 14 years: A longitudinal observartional study. Journal of Science and Medicine in Sport, 19(1), 29-34.

Brooke, H.L., Corder, K., Atkin, A.J., \& van Sluijs, E.M. (2014). A systematic literature review with meta-analyses of within-and-between-day differences in objectively measured physical activity in school-aged children. Sports Medicine, 44, 1427-1438.

Brusseau, T.A., \& Kulinna, P.H. (2015). An examination of four traditional school physical activity models on children's steps counts and MVPA. Research Quarterly for Exercise and Sport, 86(1), 88-93.

Brussea, T., Kulinna, P., Tudor-Locke, C., Van der Mars, H., \& Darst, P. (2011). Children's step counts on weekend, physical education, and non-physical education days. Journal of Human Kinetics, 27, 125-135.

Carson, V., Hunter, S., Kuzik, N., Gray, C.E., Poitras, V.J., Chaput, J.P., et al. (2016). Systematic review of sedentary behaviour and health indicators in school-aged children and youth: An update. Applied Physiology, Nutrition and Metabolism, 41(6), S240-S265.

Chilean Ministry of Health/WHO. (2005). Encuesta Mundial de Salud Escolar Chile 2004. Informe Final EMSE 2004 y 2005 Santiago. [World survey of scholar health Chile 2004, final report EMSE 2004 and 2005. In Spanish.]. Retrieved from: http://epi. minsal.cl/epi/html/invest/EMSE/INFORME\%20EMSE\%202004-2005\%20final. pdf on July 12, 2016.

Cohen, D.A., Han, B., Derose, K.P., Williamson, S., Marsh, T., \& Mckenzie, T.L. (2013). Increasing phyiscal activity in parks: Results of a randomized controlled intervention trial using community-based participatory research. American Journal of Preventive Medicine, 45(5), 590-597. 
Cole, T.J., Bellizzi, M.C., Flegal, K.M., \& Dietz, W.H. (2000). Establishing a standard definition for child overweight and obesity worldwide: International survey. BMJ, 320(7244), 1240-1243.

Cradock, A.L., Barrett, J.L., Carter, J., McHugh, A., Sproul, J., Russo, E.T., et al. (2014). Impact of the Boston Active School Day policy to promote physical activity among children. American Journal of Health Promotion, $28(3$ Suppl), S54-S64.

Currie, C., Zanotti, C., Morgan, A., Currie, D., De Looze, M., Roberts, C., et al. (2012). Social determinants of health and well-being among young people. HBSC international report from the 2009/2010 survey. Copenhagen: WHO.

Dudley, D., Okely, A., Cotton, W., Pearson, P., \& Caputi, P. (2012). Physical activity levels and movement skill instruction in secondary school physical education. Journal of Science and Medicine in Sport, 15(3), 231-237.

European Commission/EACEA/Eurydice. (2013). Physical education and sport at school in Europe Eurydice Report. Luxemburg: Publication Services of the European Union.

Evenson, K., Catellier, D., Gill, K., Ondrak, K., \& McMurray, R. (2008). Calibration of two objective measures of physical activity for children. Journal of Sports Sciences, 26(14), 1557-1565.

Fórnias, L., Machado, C., Silva, K.S., Moreira, R., França-Junior, I., Tourinho, M.F., et al. (2015). The role of school environment in physical activity among Brazilian adolescents. Plos One, 10(6), e0131342.

Gao, Z., \& Chen, S. (2014). Are field-based exergames useful in preventing childhood obesity? A systematic review. Obesity Reviews, 5, 1-16.

Gao, Z., Chen, S., Huang, C.C., Stodden, D.F., \& Xiang, P. (2017). Investigating elementary school children's daily physical activity and sedentary behavior during weekdays. Journal of Sport Sciences, 35(1), 99-104.

Gillison, F.B., Standage, M., \& Skevington, S.M. (2011). Motivation and body-related factors as discriminators of change in adolescents' exercise behavior profiles. Journal of Adolescent Health, 48, 44-51.

Godard, C., Román, M., Rodríguez, M.P., Leyton, B., \& Salazar, G. (2012). Variability of physical activity in Chilean children aged 4-10: A study by accelerometry. Archivos Argentinos de Pediatría, 110(5), 388-393.

González, S.A., Sarmiento, O.L., Cohen, D.D., Camargo, D.M., Correa, J.E., Páez, D.C., et al. (2014). Results from Colombia's 2014 Report Card on physical activity for children and youth. Journal of Physical Activity and Health, 11(Supp1), S33-S44.

Government of Chile. (2013). Chiledeporte: Encuesta nacional de hábitos de actividad física y deporte en la población chilena igual o mayor a 18 años. [National survey of physical activity habits in Chilean population of 18 years. In Spanish.]. Retrieved from: http://es.slideshare.net/claudiaserey/encuesta-nacionalhabitosactividadfisicayde portiva on March 25, 2017.

ISAK. (2001). International standards for anthropometric assessment. Underdale: International Society for the Advancement of Kinanthropometry.

Kain, J., Concha, F., Moreno, L., \& Leyton, B. (2014). School-based obesity prevention intervention in Chilean children: Effective in controlling, but not reducing obesity. Journal of Obesity, Article ID 618293. doi: 10.1155/2014/618293

Lee, H., Tamminen, K.A., Clark, A.M., Slater, L., Spence, J.C., \& Holt, N.L. (2015). A meta-study of qualitative research examining determinants of children's independent active free play. International Journal of Behavioral Nutrition, $12,5$.

Longmuir, P., Colley, R., Wherley, V., \& Tremblay, M. (2014). Risks and benefits of childhood physical activity. Lancet Diabetes Endocrinology, 2, 861-862.

Mayorga-Vega, D., Martínez-Baena, A., \& Viciana, J. (2018). Does school physical education really contribute to accelerometer-measured daily physical activity and non sedentary behaviour in high school students? Journal of Sports Sciences, 36(17), 1913-1922. doi: 10.1080/02640414.2018.1425967

Mayorga-Vega, D., \& Viciana, J. (2015). Differences in physical activity levels in school-based contexts. Influence of gender, age, and body weight status. Kinesiology, 47(2), 151-158.

Merrill, R.M., Shields, E.C., White, G.L., \& Druce, D. (2005). Climate conditions and physical activity in the United States. American Journal of Health Behavior, 29(4), 371-381.

Mielgo-Ayuso, J., Aparicio-Ugarriza, R., Castillo, A., Ruiz, E., Ávila, J.M., Aranceta-Batrina, J., et al. (2016). Physical activity patterns of Spanish population are mostly determined by sex and age. Findings in the ANIBES study. Plos One 11(2), e0149969.

Moore, J.B., Brinkley, J., Morris, S.F., Oniffrey, T.M., \& Kolbe, M.B. (2016). Effectiveness of community-based minigrants to increase physical activity and decrease sedentary time in youth. Journal of Public Health, Management and Practice, 22(4), 370-378.

Moreno, L., Cano, M., Orellana, Y., \& Kain, J. (2015). Compliance of physical activity guidelines by Chilean low-income children: Difference between school and weekend days and nutritional status. Nutrición Hospitalaria, 31(5), 2195-2201.

Morrissey, J.L., Janz, K.F., Letuchy, E.M., Shelby, L.F., \& Steven, M.L. (2015). The effect of family and friend support on physical activity through adolescence: A longitudinal study. BMC International Journal of Behavioral Nutrition and Physical Activity, 12, 103.

Muros, J.J., Cofre-Bolados, C., Zurita-Ortega, F., Castro-Sánchez, M., Linares-Manrique, M., \& Chacón-Cuberos, R. (2016). Relación entre condición física, actividad física y diferentes parámetros antropométricos en escolares de Santiago (Chile). [Relationship between physical fitness, physical activity and different anthropometric parameters in scholars from Santiago (Chile). In Spanish.]. Nutrición Hospitalaria, 33(2), 314-318.

Oliver, M., Badland, H.M., Schofield, G.M., \& Shepherd, J. (2011). Identification of accelerometer nonwear time and sedentary behavior. Research Quarterly for Exercise and Sport, 82(4), 779-783. 
Parrish, A., Yeatman, H., Iverson, D., \& Russell, K. (2012). Using interviews and peer pairs to better understand how school environments affect young children's playground physical activity levels: A qualitative study. Health Education Research, 27(2), 269-280.

Recio-Rodríguez, J.I., Agudo-Conde, C., Martín-Cantera, C., González-Viejo, M.N., Fernández-Alonso, M.C., Arietaleanizbeaskoa, M.S., et al. (2016). Short-term effectiveness of a mobile phone app for increasing physical activity and adherence to the Mediterranean diet in primary care: A randomized controlled trial (EVIDENT II Study). Journal of Medicine Internet Research, 18(12), e331.

Ridgers, N.D., Stratton, G., \& Fairclough, S.J. (2006). Physical activity levels of children during school playtime. Sports Medicine, 36(4), 359-371.

Ridgers, N.D., Timperio, A., Crawford, D., \& Salmon, J. (2013). What factors are associated with adolescents' school break time physical activity and sedentary time? Plos One 8(2), e56838.

Santos-Lozano, A., Santín-Medeiros, F., Cardon, G., Torres-Luque, G., Bailón, R., Bergmeir, C., et al. (2013). Actigraph GT3X: Validation and determination of physical activity intensity cut points. International Journal of Sports Medicine, 34(11), 975-982.

Sedentary Behaviour Research Network. (2012). Letter to the editor: Standardized use of the terms "sedentary" and "sedentary behaviours." Applied Physiolology, Nutrition and Metabolism, 37(3), 540-542.

Silva, P., Santos, R., Welk, G., \& Mota, J. (2011). Seasonal differences in physical activity and sedentary patterns: The relevance of the PA context. Journal of Sports Science and Medicine, 10(1), 66-72.

Stanley, R.M., Boshoff, K., \& Dollman, J. (2012). Voices in the playground: A qualitative exploration of the barriers and facilitators of lunchtime play. Journal of Science and Medicine in Sport, 15(1), 44-51.

Treuth, M.S., Schmitz, K., Catellier, D.J., McMurray, R.G., Murray, D.M., Almeida, M.J., et al. (2004). Defining accelerometer thresholds for activity intensities in adolescent girls. Medicine and Science in Sports and Exercise, 36(7), 1259-1266.

Trost, S.G., Loprinzi, P.D., Moore, R., \& Pfeiffer, K.A. (2011). Comparison of accelerometer cut points for predicting activity intensity in youth. Medicine and Science in Sports and Exercise, 43(7), 1360-1368.

Tudor-Locke, C., Craig, C., Beets, M., Belton, S., Cardon, G., Duncan, S., et al. (2011). How many steps/day are enough for children and adolescents. International Journal of Behavioral Nutrition and Physical Activity, 8, 78.

United States Department of Health and Human Services. (2010). Strategies to improve the quality of Physical Education. Washington: Centers for Disease Control and Prevention.

Uys, M., Draper, C.E., Hendricks, S., Villiers, A., Fourie, J., Steyn, N., et al. (2015). Factors influencing break-time physical activity of South African primary school learners from low-income communities. Journal of Physical Activity and Health, 12(5), 618-627.

Viciana, J., Martínez-Baena, A., \& Mayorga-Vega, D. (2015). Contribución de la educación Física a las recomendaciones diarias de actividad física en adolescentes según el género; un estudio con acelerometría. [Contribution of PE to daily recommendations of physical activity in adolescents according to gender: A study with accelerometry. In Spanish.]. Nutrición Hospitalaria, 32, 1246-1251.

Viciana, J., Mayorga-Vega, D., \& Martínez, A. (2016). Moderate-to-vigorous physical activity levels in Physical Education, school recess, and after-school-time. Influence of gender, age, and weight status. Journal of Physical Activity and Health, 13, 1117-1123.

Watson, A., Eliott, J., \& Mehta, K. (2015). Perceived barriers and facilitators to participation in physical activity during the school lunch break for girls aged 12-13 years. European Physical Education Review, 21(2), 257-271.

Win, A.M., Yen, L.W., Tan, K.H., Tar, R.B., Chia, K.S., \& Mueller-Riemenschneider, F. (2015). Patterns of physical activity and sedentary behavior in a representative sample of multi-ethnic South-East Asian population: A cross-sectional study. BMC Public Health, 15, 318.

WHO - World Health Organization. (2010). Global recommendation on physical activity for health. Geneve: WHO.

Yli-Piipari, S., Santeri, J., Jaakkola, T., Hakonen, H., Cole, J., \& Tammelin, T. (2016). Objectively measured school day physical activity among elementary students in the United States and Finland. Journal of Physical Activity and Health, 13, 440-446.

Submitted: April 24, 2017

Accepted: October 1, 2018

Published Online First: November 15, 2019
Correspondence to:

Jesús Viciana, Ph.D.

Department of Physical Education and Sport

University of Granada, Spain

Ctra. Alfacar s/n, 18011, Spain

Telephone: +34958246641

Fax: +34 958244369

E-mail: jviciana@ugr.es

\section{Acknowledgments}

Authors want to thank Aliisa Hatten for the English revision of this manuscript. Special thanks for all the participants and school centers that participated in this study. 